\title{
As ficções de fã e o Ensino de Línguas por Tarefas
}

DOI: http://dx.doi.org/10.21165/el.v48i2.2173

\section{William Danilo Garcia'}

\section{Resumo}

Este artigo objetiva discutir os benefícios de se usar a literatura em aulas de inglês e fornecer um plano de aula com foco na produção escrita como forma de evidenciar essa discussão. Assim, as ficções de fã e o Ensino de Línguas por Tarefas foram utilizados como elementos chave no desenvolvimento dessa aula. Sobre a metodologia, este artigo descreve o Ensino de Línguas por Tarefas, o universo literário das ficções de fã e, finalmente, esse plano de aula cujo objetivo é a produção escrita de uma ficção de fã. Referente à abordagem metodológica que embasa essa aula, destacam-se Prabhu (1987), Skehan (1996), Willis, (1996), Nunan (2004) e Ellis (2006), a respeito do Ensino de Línguas por Tarefas; Jenkins (2012) e Neves (2014), que discorrem sobre as ficções de fã, e Dalvi (2012) sobre os usos e benefícios da literatura em uma aula de línguas. Em relação aos resultados, uma atividade respaldada pelos padrões do Ensino de Línguas por Tarefa foi estabelecida de acordo com os seguintes estágios: alunos foram expostos à literatura dos fãs durante a Pré-Tarefa e, então, dada a oportunidade de redigirem suas próprias ficções de fã, que constituiu a fase da Tarefa. Por fım, por meio dessa atividade, foi possível evidenciar que os alunos puderam usar a língua de forma mais autêntica e significativa.

Palavras-chave: tarefa; literatura; ficção de fã.

1 Universidade Estadual Paulista (UNESP), São José do Rio Preto, São Paulo, Brasil; wil.danilo@hotmail.com; https://orcid.org/0000-0001-6898-1931 


\title{
Fan fictions and Task-Based Language Teaching
}

\begin{abstract}
The purpose of this article is to discuss the benefits of using literature in English classes and to provide a class plan that focuses the writing skill to support this discussion. Fan fictions and Task-Based Language Teaching, then, were used as key factors in the development of this class. About the methodology, this article describes the Task-Based Language Teaching, the universe of fan fictions and, finally, this class in which the objective is the written production of a fan fiction. Therefore, in relation to the methodological approach that guides this class, it is important to highlight Prabhu (1987), Skehan (1996), Willis (1996), Nunan (2004) and Ellis (2006), for the Task-Based Language Teaching. Jenkins (2012) and Neves (2014), regarding fan fictions, and Dalvi (2012) concerning the uses and benefits of literature in a language class. In regard to the findings, an activity based on the standards of Task-Based Language Teaching was developed under the following class procedures: students were firstly exposed to the fan literature during the Pre-Task phase and then given the opportunity to write their own fan fiction, which constitutes the Task phase. Lastly, through this activity, it was possible to evidence that students were able to use the language in a more meaningful way.
\end{abstract}

Keywords: task; literature; fan fiction.

\section{Introdução}

As ficções de fã, como aponta Neves (2014, p. 100), são "histórias alternativas em prosa [...] escritas por fãs de determinada série ou fandom.". Nessas narrativas, observa-se uma escrita criativa em que os fãs fazem uso dos mais diversos universos, tais como, séries de televisão, filmes, games e outros que possam Ihes interessar, como apresenta Jenkins (2012).

Desse modo, visando essa liberdade de criação proporcionada pelas ficções de fã sobre diferentes temas e até mesmo outras obras literárias (como a saga Harry Potter, por exemplo), este artigo visa, por meio da elaboração de um plano de aula nos parâmetros do Ensino de Línguas por Tarefas, utilizar das contribuições da área da literatura como forma de dar embasamento às considerações concernentes a essa metodologia de ensino que enfatiza o uso autêntico da língua.

Essa utilização de materiais autênticos (no caso, as ficções de fãs) em salas de aula presenciais com o intuito de elaborar aulas de língua inglesa pode ser vista de forma positiva, pois como aponta Silva (2001, p. 171, tradução minha), 
[...] o uso da literatura é uma forma eficaz de prender a atenção do aluno. Além de alcançar os objetivos de aprendizagem, os textos literários fazem com que o processo de ensino/aprendizagem seja uma experiência divertida e cativante para ambos os professores e alunos ${ }^{2}$.

Como se observa, a literatura contribui positivamente para a realização de uma aula de língua no sentido de promover um ambiente mais engajador. Assim, somando esse fator àquilo que o Ensino por Tarefas propõe - uma comunicação significativa -, entende-se que essa aula disponibilizará mais abertura a discussões e aos processos que permeiam a aprendizagem. Vê-se, portanto, nas ficções de fã uma forma de não apenas trazer a literatura para o ambiente de aprendizagem de inglês, mas também tornar possível a produção escrita de um texto de fã como uma tarefa a ser desenvolvida durante uma aula. Sem mais, o que se desenvolverá, portanto, neste artigo é a proposta de como tornar essa utilização da literatura possível em sala de aula.

\section{0 Ensino de Línguas por Tarefas}

Antes de aprofundar nos conceitos do Ensino de Línguas por Tarefas - também conhecido pelo acrônimo TBLT, do inglês Task-Based Language Teaching -, julga-se necessário compreender como seu surgimento ocorreu. Nesse sentido, quanto aos trabalhos pioneiros em Tarefa, tem-se o projeto de Prabhu (1987).

O Ensino por Tarefas teve sua origem na Índia com o trabalho inaugural de Prabhu (1987). Em seu projeto, o foco era propor uma abordagem que rompesse com a pedagogia vigente até então. Nessa ruptura, o que se buscava era "a preocupação com os alunos e com o sentido e o esforço que se resultava ao entender e dizer as coisas." (PRABHU, 1987, p. 22). Rejeitou-se, assim, o foco na forma ou na pré-seleção do conteúdo linguístico a ser ensinado. Ainda nesse sentido, Skehan (1996) ressalta que o surgimento do Ensino por Tarefas se deu em detrimento ao PPP (no inglês Presentation, Practice e Production), cuja ênfase recai sobre a automatização da forma e sua sistematização feita de forma segregada.

Com esse cenário da criação e os primeiros trabalhos acerca de tarefa em mente, é relevante perpassar algumas das definições que foram elaboradas sobre o Ensino por Tarefas. Destaca-se, inicialmente, a definição de Tarefa como "uma atividade que requer dos alunos chegar a um resultado a partir de uma dada informação e a partir do processo

2 No original: "Using literature is an effective way of apprehending the learner's attention. Besides achieving the learning objectives, literary texts make the teaching/learning process a fun and attractive experience for both teachers and students.". 
do pensamento, permitindo ao professor controlar e regular esse processo."3 (PRABHU, 1987, p. 24, tradução minha). Nota-se que, em uma definição precursora, Prabhu já enfatizava o fato de a Tarefa demandar do aluno um esforço cognitivo para que se alcance um resultado.

Essa noção de resultado é retomada em outras definições, como na de Skehan (1996, p. 20, tradução minha): "atividades que trazem o sentido como foco principal. O sucesso em uma tarefa é avaliado em termos do resultado alcançado e as tarefas geralmente apresentam certa semelhança com o uso da língua na vida real."4. Percebe-se que o autor reforça a importância da mensagem ao invés da forma e afirma que a realização da Tarefa se assemelha à utilização da língua feita em alguma situação da vida real.

Outra definição relevante é a de Willis (1996, p. 23, tradução minha) em que tarefas são "atividades em que a língua alvo é usada pelo aprendiz com um propósito comunicativo no intuito de se alcançar um resultado." ${ }^{.5}$. Entende-se esse resultado como aquilo que se alcançaria a partir do uso autêntico da língua em uma situação real de comunicação, por exemplo, a realização de um pedido em um restaurante. Nunan (2004) parece concordar com essa percepção, pois apontaria que esse pedido em um restaurante é uma tarefa que os falantes realizam no mundo real. Nesse sentido, o que se observa em uma Tarefa realizada em sala de aula é uma simulação dessa situação comunicativa real, denominada real-world task pelo autor. Sendo assim, Nunan (2004) recomenda que as atividades feitas no ambiente de ensino devem se espelhar no uso real da língua.

Em seguida, ainda nessa perspectiva das definições de tarefa, tem-se a colocação de Nunan (2004, p. 4, tradução minha) que diz que tarefa é

[...] um pedaço de trabalho de sala de aula que envolve o aluno em compreender, manipular, produzir ou interagir na língua alvo enquanto a atenção é voltada em mobilizar o conhecimento gramatical no objetivo de expressar sentido. Sendo assim, a intenção é transmitir sentido ao invés de manipular a forma. Além disso, a tarefa deve

3 No original: "An activity wich required learners to arrive at an outcome from given information through some process of thought, and which allowed teachers to control and regulate that process, was regarded as a 'task'."

4 No original: "Tasks, in this viewpoint, are activities which have meaning as their primary focus. Success in the task is evaluated in terms of achievement of an outcome, and tasks generally bear some resemblance to real-life language use."

5 No original: "[...] tasks are always activities where the target language is used by the learner for a communicative purpose (goal) in order to achieve an outcome." 
haver um senso de completude e ser capaz de se sustentar como um ato comunicativo com um começo, meio e fim ${ }^{6}$.

Nota-se que o teórico também enfatiza o fato de a Tarefa não trazer foco à manipulação de itens linguísticos, mas ao processo de mobilização daquilo que o aluno já saiba na construção e transmissão de sentido em um ato comunicativo que tenha um propósito, tal como o de fazer um pedido em um restaurante.

Vale ainda a ressalva sobre as características dessa metodologia, que parecem concluir bem esse panorama a respeito das definições dessa atividade. Esses aspectos consideram o fato de a tarefa: "(i) ter o significado como primordial, (ii) não dar ao aluno o significado de outra pessoa para que ele o reproduza, (iii) haver certa relação com o mundo real, (iv) ter algumas prioridades com relação a sua realização e (v) relacionar o resultado à avaliação resultado"7. (SKEHAN, 1998 apud NUNAN, 2006, p. 16, tradução minha).

Por fim, em uma proposta de classificar os tipos de tarefas, Willis (1996) as categoriza em: Tarefas de listar, de ordenar ou de separar, de comparar, de resolver problemas, de compartilhar experiência pessoal e tarefas criativas. A autora acrescenta ainda que as tarefas podem ser de cunho mais fechado ou aberto, a depender do objetivo da tarefa que pode ser mais ou menos específico.

Em uma breve conclusão, foi visto que a Tarefa pode acontecer na sala de aula de diferentes formas - conforme a categorização proposta por Willis (1996) - e que embora possuam um cunho pedagógico, essas atividades se espelham nas Tarefas que são feitas no mundo real. Sendo assim, o objetivo dessa atividade recai sobre o sentido que se constrói a partir do uso autêntico da língua ao invés de um uso cujo objetivo seja praticar determinado item gramatical ou lexical.

6 No original: "[...] task is a piece of classroom work that involves learners in comprehending, manipulating, producing or interacting in their target language while their attention is focused on mobilizing their grammatical knowledge in order to express meaning, and in which the intention is to convey meaning rather than to manipulate form. The task should also have a sense of completeness, being able to stand alone as a communicative act in its own right with a beginning, a middle and an end.".

7 No original: "Meaning is primary; learners are not given other people's meaning to regurgitate; there is some sort of relationship to comparable real-world activities; task completion has some priority; the assessment of the task is in terms of outcome.". 


\subsection{As etapas de uma Tarefa}

Visto o que pode ser considerado e/ou definido como uma Tarefa e as características necessárias a essa atividade, é preciso entender como estruturá-la para que seja aplicada em sala de aula sem desconsiderar seu caráter comunicativo e de uso autêntico e/ou significativo de língua.

Percebe-se, na literatura de Ensino por Tarefas, que há certo consenso em relação aos estágios que perpassam essa atividade. Desde o projeto inicial encabeçado por Prabhu (1987) já se pode observar essa preocupação com a aplicação dessas atividades ao se deparar com os estágios propostos pelo autor: a Pré-Tarefa e a Tarefa. Em seguida, tanto em Skehan (1996) quanto em Willis (1996), encontra-se a divisão das etapas em PréTarefa, Tarefa em si e a Pós-Tarefa.

Willis (1996) foi responsável por uma proposta mais detalhada em que a fase da PósTarefa leva em consideração atividades com um foco mais linguístico. Assim, o intuito é o de se alcançar uma estruturação mais abrangente dos estágios envolvidos nessa metodologia. Nota-se também que alguns autores mais contemporâneos, como Nunan (2004) e Ellis (2006), parecem concordar com essa organização das etapas de uma tarefa. Será justamente com base na proposta de Ellis (2006) destacada na seção a seguir, que este artigo se propõe a elaborar uma Tarefa que aproxime a literatura ao Ensino de Línguas por Tarefas.

\subsubsection{A etapa da Pré-Tarefa}

A primeira das três fases de uma Tarefa é intitulada Pré-Tarefa, cujo objetivo éo de "preparar os estudantes para realizar a tarefa de modo a promover aquisição"8. (ELLIS, 2006, p. 21, tradução minha). Desse modo, a grande importância desse momento é a preparação e a motivação, que trará mais êxito para a fase em que a tarefa será desenvolvida. Como pontuam Richards e Rodgers (2001, p. 223, tradução minha), "engajar os estudantes em uma tarefa fornece um contexto melhor para a ativação do processo de aprendizagem." 9 .

Para que esse engajamento aconteça, Ellis (2006) sugere algumas opções de se ter uma Pré-Tarefa, que podem ser a realização de uma atividade parecida à Tarefa que será realizada na fase da tarefa em si. Desse modo, a vantagem descrita por Ellis (2006) está na eliminação de explicações longas do que será feito, além de facilitar o entendimento da tarefa em si.

8 No original: "[...] prepare students to perform the task in ways that will promote acquisition.."

9 No original: "Engaging learners in task work provides a better context for the activation of learning process.". 
Outra forma apresentada é o fornecimento de um modelo, o que implica "pedir que os alunos observem um modelo de como a tarefa deve ser cumprida sem exigir dos mesmos que façam uma realização prévia da tarefa."10 (ELLIS, 2006, p. 22, tradução minha). 0 pesquisador acrescenta ainda que essa medida envolve a introdução de um texto oral ou escrito para que se exemplifique o que se objetiva com a tarefa.

Em terceiro lugar, é possível que a Pré-Tarefa envolva uma atividade que não seja, necessariamente, uma Tarefa, mas que forneça aos alunos a demanda linguística necessária para que essa seja desenvolvida. Comumente, essa preparação inclui os itens lexicais que subsidiarão a performance da Tarefa. Contudo, deve-se atentar ao fato de que "há sempre o risco de que o pré-ensino de vocabulário fará como que os aprendizes tratem a tarefa como uma oportunidade de se praticar as palavras pré-selecionadas."11 (ELLIS, 2006, p. 23, tradução minha). Portanto, é de extrema relevância que o professor seja cauteloso ao fornecer fontes de pesquisa ou lidar com o pré-ensino de vocabulário ou de qualquer outro item linguístico, afınal a Tarefa não objetiva manipular a língua, mas sim produzir significado.

Por fim, o planejamento estratégico é a quarta sugestão da Pré-Tarefa e significa dar a oportunidade aos alunos de planejar a quantidade de tempo que precisarão para o desenvolvimento da Tarefa. Além do quesito tempo, esse momento também poderá envolver o planejamento da forma e da estrutura a qual eles precisarão recorrer para que a Tarefa seja executada.

\subsubsection{A etapa durante a Tarefa}

Considerada a Pré-Tarefa, o foco recai sobre a fase da Tarefa em si. Conforme Ellis (2006), essa etapa oferece três condições que podem ser disponibilizadas aos alunos e que influenciarão diretamente a forma como os aprendizes conduzirão e realizarão a tarefa. A primeira condição é a de a Tarefa envolver ou não a determinação de um limite de tempo para que se chegue a um resultado. A segunda envolve a decisão de permitir ou não que os alunos acessem o material de insumo utilizado na fase da Pré-Tarefa. Já a terceira condição consiste na decisão de apresentar ou não algum elemento surpresa durante a realização da Tarefa pelos alunos.

Quanto à primeira opção de realização da Tarefa, essa se refere à execução da atividade sob pressão de tempo ou não. Assim, o professor pode disponibilizar tempo suficiente para que se faça a Tarefa ou sugerir um limite de tempo. De acordo com Ellis (2006),

10 No original: "An alternative is to ask the students to observe a model of how the task can be performed without requiring them to undertake a trial performance of the task.".

11 No original: "However, there is always the danger that pre-teaching vocabulary will result in learners treating the task as an opportunity to practice pre-selected words.". 
há estudos que apontam que se o foco for acuidade, trabalhar sem a estipulação de um tempo limite pode ser a melhor escolha; enquanto se o que se visa for fluência, o limite de tempo fará com que os alunos pensem menos nas formas que serão utilizadas. Isso ocorre porque quando há tempo de sobra para se completar a Tarefa, haverá a possibilidade de os alunos manterem uma atenção maior na forma. Por outro lado, quando o tempo é escasso, a pressão no objetivo de se concluir a atividade aumenta e o monitoramento com a forma perde espaço.

A segunda opção, como descreve Ellis (2006), relaciona-se com o fato de permitir que os estudantes tenham ou não acesso ao material de insumo da Tarefa. Essa é uma questão relevante, pois se há contato com o material, os alunos podem recorrer a ele para pegar alguma informação emprestada. Contudo, é importante que esteja claro aos alunos que o ideal é pegar informação emprestada com o intuito de se expressar e produzir (um dos principais objetivos da tarefa) e não com o foco de reproduzir o que o material já aponta.

Por fım, a terceira alternativa para as opções de realização da Tarefa é a de introduzir algum elemento surpresa a essa atividade. Segundo Ellis (2006), apresentar informação nova faz com que a produção e a interação entre os estudantes aumentem.

Além dessas três opções, Ellis (2006) sugere que pode ser dada a oportunidade de ambos, professor e aluno, decidirem a respeito de como a Tarefa deve ser realizada. Nesse sentido, o autor afirma que "o modo como professores e alunos conduzirão a tarefa será influenciado, de maneira geral, pelas experiências anteriores de ensino e aprendizagem e pelas próprias definições pessoais da situação de ensino-aprendizagem em particular."12 (ELLIS, 2006, p. 29, tradução minha).

Esse apontamento se mostra bastante relevante, pois ressalta a importância do papel do professor e do aluno na realização de uma Tarefa, evidenciando, portanto, o quanto o conhecimento prévio de ambos corrobora para o êxito da Tarefa.

\subsubsection{A etapa da Pós-Tarefa}

Como aborda Ellis (2006, p. 36, tradução minha), o propósito dessa fase é "dar a oportunidade para que o aluno repita o desempenho tido na tarefa, encorajar reflexão em como a tarefa foi executada e chamar atenção para a forma e estrutura [...]."13.

12 No original: "How teachers and learners conduct a task will be influenced, to a large extent, by their prior experiences of teaching and learning and their personal definitions of the particular teaching-learning situation.".

13 No original: "[...] to provide an opportunity for a repeat performance of the task, to encourage reflection on how the task was performed, and to encourage attention to form [...]". 
Sendo assim, os benefícios de se repetir a Tarefa incluem a melhora na produção, o aumento na complexidade e na forma de expressão, o que resulta em uma maior fluência. Acrescenta-se ainda, segundo Ellis (2006), que essa repetição pode ser pública, envolvendo, de um lado, o aumento do estresse pelos alunos e a possível diminuição da fluência por conta disso; mas, por outro lado, dando aos alunos a chance de realizarem apresentações mais formais.

Ellis (2006) também diz que escrever feedbacks ou o fazer de forma oral pode ser uma forma de se concluir uma Tarefa. Contudo, o autor destaca a importância desse comentário conter considerações no conteúdo, no resultado, e no desempenho do aluno. Além disso, Ellis (2006) indica que esses apontamentos devem permitir que os alunos reflitam sobre seu desempenho no intuito de pensarem como eles podem melhorar, possibilitando a reflexão acerca das estratégias metacognitivas. Uma última recomendação do autor é a de que os estudantes avaliem a Tarefa para que o professor saiba quando usá-la novamente.

Por fim, a terceira proposta para a Pós-Tarefa é a de enfatizar a forma e a estrutura. Ellis (2006) expõe que isso pode ser feito após o término da Tarefa sem comprometer seus princípios. Contudo, o autor indica que, apesar de os pesquisadores proporem que os feedbacks de teor linguístico ocorram de forma posterior à tarefa, "o foco na estrutura e na forma constitui uma valiosa opção para a fase de desenvolvimento da tarefa e isso é bastante compatível com o objetivo primeiro dessa atividade, que é o conteúdo da mensagem [...]."14 (ELLIS, 2006, p. 38, tradução minha).

Assim, para que se pratique a estrutura, Ellis (2006) apresenta algumas opções de atividades, como (i) rever, na Pós-Tarefa, os principais erros cometidos durante a Tarefa; (ii) apresentar aos alunos os erros mais recorrentes e pedir que eles os reconheçam e busquem saná-los; (iii) propor exercícios de produção, tais como repetição, substituição e etc. e (iv) propor atividades, como de transcrição, para que os alunos se ouçam e percebam os desvios feitos durante a realização da Tarefa.

\section{Literatura e o ensino de línguas}

Ao se pensar no uso de literatura no contexto de ensino de línguas, logo se conclui que ela é uma maneira de proporcionar aos estudantes o contato com materiais autênticos da língua-alvo, como sugerem Silva (2001) e Llach (2007). Cabe dizer que materiais autênticos são aqueles que não são produzidos para aprendizes de uma segunda língua, ou seja, textos que não têm uma finalidade pedagógica (PEACOCK, 1997).

14 No original: "I have emphasized that a focus on form constitutes a valuable during-task option and that it is quite compatible with a primary focus on message content, which is the hallmark of a task.". 
Contudo, é relevante acrescentar, como demonstra Silva (2001), que a literatura também beneficia o enriquecimento cultural e linguístico, sem mencionar o envolvimento pessoal mais aprofundado por parte dos professores e dos alunos nas discussões que a literatura pode promover nas aulas - fator considerado relevante por Richards e Rodgers (2001) com relação ao contexto de aprendizagem de língua. Nos dizeres de Silva (2001, p. 173, tradução minha), quando os estudantes estão engajados, "[...] eles prestam menos atenção ou até mesmo se esquecem das dificuldades que possam ter com relação a vocabulário ou a qualquer outro aspecto da língua-alvo."15. Um bom engajamento dos alunos pode ocorrer via literatura.

Outra questão relevante é a de a leitura deixar "vir à tona quem somos, o que pensamos, o que sabemos, o que ignoramos [...]" (DALVI, 2012, p. 21), justamente pelo fato de o ato de ler ser único, já que "um mesmo texto é recebido de diferentes maneiras por diferentes pessoas, e em diferentes épocas ou sociedades." (DALVI, 2012, p. 23).

Por esse viés, torna-se tangível compreender que "um texto literário possui múltiplas interpretações, que geram opiniões diferentes entre os leitores e isso leva à interação real e motivada com o texto, com os outros alunos e com o professor."16 (WIDDOWSON, 1983 apud LLACH, 2007, p. 9, tradução minha). Essa interação real e motivada não só com o texto, mas também entre os alunos e professores, pode ser compreendida como uma oportunidade de se estabelecer alguns dos princípios de uma Tarefa, como a criação e a negociação de significado por meio do uso e não da manipulação da língua.

Desse modo, vê-se que a literatura pode desenvolver não somente a competência linguística ao oferecer material autêntico, mas também a competência comunicativa uma vez que oferece oportunidades de se comparar e discutir possíveis interpretações de uma mesma obra. Por fim, Llach (2007, p. 10, tradução minha) ainda recorre a Ramsaram (1983) para salientar que "[...] o uso de literatura para o ensino de língua não contribui só para um melhor entendimento linguístico, o desenvolvimento de habilidades criativas ou um maior nível de proficiência. Ela também estabelece uma contribuição para a apreciação literária."17.

15 No original: "In short, the students are engaged in the plot that they pay little attention to or even forget about the difficulties they might have regarding vocabulary or any other aspects of the target language.".

16 No original: "[...] a literary text has multiple interpretations, these generate different opinions among the learners and this leads to real, motivated interaction with the text, with the fellow students and with the teacher.".

17 No original: "Using literature to teach language not only contributes to a better linguistic understanding, a development of creative skills, and a higher language proficiency, it also makes an important contribuition to literary appreciation.". 
Assim, para que se tenha uma junção entre a apreciação literária (também relacionada com a motivação e o engajamento dos alunos) e os benefícios que ela agrega ao ensino de língua concebido via tarefa (proporcionando discussões e produção de significado), este artigo utilizará das produções textuais feitas pelos fãs - as chamadas ficções de fã - para que se possa estabelecer uma atividade de tarefa que compile muitas das considerações discutidas até então.

\section{As ficções de fã}

Antes de se aprofundar nas ficções de fã, que serão utilizadas no intuito de se aproximar a literatura a uma aula nos padrões do Ensino por Tarefas, é essencial considerar que o fato de recriar histórias não é exatamente uma prática apenas da contemporaneidade.

Como descreve Neves (2014, p. 93),

[...] recontar uma história com base em personagens criados por terceiros era uma prática comum nos tempos passados, principalmente nas comunidades orais, cuja extensão da memória não dava conta de se prender aos fatos "originais" por muito tempo, por essa razão era necessário alterar os fatos e, consequentemente, novos discursos podem surgir ou serem integrados no primeiro discurso [...].

As ficções de fã, apesar de não serem necessariamente resultantes das comunidades orais, apresentam características semelhantes a esse ato de recontar ou inserir novos elementos a um discurso já existente. Afınal de contas, essas histórias fictícias são, de certo modo, formas alternativas que os fãs criam a partir de algum universo que lhes seja interessante. Nos dizeres de Neves (2014, p. 100), lê-se

[...] as fanfictions ou simplesmente fanfics são histórias alternativas em prosa [...] escritas por fãs de determinada série ou fandom. Nelas, o autor (ou autores) pode colocar os conhecidos personagens das mais variadas séries [...] e livros em novas situações. As situações podem variar de pequenos contos a sagas, dependendo da escolha do autor. Pode-se também criar finais alternativos para os personagens, explorar melhor personagens secundários e colocar os personagens em situações novas que não existiam na obra original.

Como se observa na citação, essas histórias criadas por fãs apresentam como principal característica a liberdade de criação do fã, independente do universo do qual ele decida escrever. Sendo assim, é muito comum encontrar histórias acerca de cantores ou 
bandas, livros, filmes, séries, animes e muitos outros universos dos quais o fã julgue interessante redigir uma história. Além disso, vale apontar que essa característica mais livre, por assim dizer, também se aplica ao modo como o fã decide recriar uma história. Desse modo, é possível adicionar ou subtrair personagens, assim como inseri-los em um contexto diferente da obra ou do universo em que o personagem estaria envolvido. Há a possibilidade de recriar contextos, por exemplo, inserir o universo de magia e bruxaria da saga Harry Potter à vida "real". Enfim, infinitas são as possibilidades disponíveis aos fãs em suas histórias.

Percebe-se, portanto, o quanto esse tipo de literatura democratiza e dissemina o que Neves (2014) descreve como cultura de fã. Para o autor, essa cultura de fã é o que instiga os fãs a consumirem produtos derivados da cultura de massa. No entanto, é o que incentiva que aqueles que muito apreciam determinado universo criem novos produtos culturais. Para Neves (2014), é exatamente esse perfil de produtor instigado no fã que o leva a redigir e ser participante do ciberespaço ou espaço virtual.

Sendo assim, no que diz respeito a como essas produções literárias são veiculadas, há de se dizer que essas histórias são hospedadas e amplamente acessadas em sites como o fanfiction.net, por exemplo. Para se ler, portanto, uma ficção de fã, é preciso escolher a categoria que se deseja (como livros, séries de TV e etc.). Feito isso, o leitor é direcionado aos títulos dos filmes, livros ou seriados em que já foram usados como temática para a elaboração de ficções de fã. Selecionado o que se quer ler, o site o conduz a uma página em que se observa não só o título, como também uma breve descrição de cada produção textual. É possível também nessa busca por acessar tais obras, deparar-se com a classificação etária, que pode ser $\mathrm{G}$ ou $\mathrm{K}$ quando disponibilizadas a todas as idades; $\mathrm{K}+$ quando não recomendada a menores de nove anos; PG-13, NC-13 ou T quando indicadas a maiores de 13 anos; PG-15, NC-15 ou M para maiores de 15 anos e PG-17, NC-17, NC-18 ou MA quando não recomendadas para menores de idade por conta do conteúdo.

Ainda com relação à cultura de fã, Neves (2014) traz uma consideração muito relevante no sentido de as fanzines (revistas de fã surgidas em meados da década de 80) serem um dos primeiros exemplos dessa cultura. Neves (2014) aponta também em sua obra que são exatamente as fanzines que impulsionaram o surgimento das ficções de fã, uma vez que essas revistas tinham os fãs como público-alvo e eram também redigidas por eles.

Outras contribuições importantes no que diz respeito às ficções de fã são os apontamentos de Jenkins (2012). Para o autor, é interessante ressaltar os motivos pelos quais os fãs criam e escrevem histórias pautadas em uma obra já existente. Como ele mesmo alega, "podemos reescrever um texto por fascinação ou frustração ou muitas vezes uma fusão complexa de ambos." (JENKINS, 2012, p. 13). A tais frustrações e fascinações, Jenkins (2012) estipula os conceitos de sementes, buracos, contradições, silêncios e potenciais. 
De acordo com Jenkins (2012, p. 16), sementes são "pedaços de informação introduzidos na narrativa para indicar um mundo maior que não é completamente desenvolvido na própria história.". Já sobre os buracos, aponta-se que são "elementos narrativos dos quais os leitores sentem falta e que são centrais à sua compreensão dos personagens." (Ibidem, p. 17). Com relação às contradições, é dito que são "dois ou mais elementos na narrativa (intencionais ou não) sugerindo possibilidades alternativas para os personagens." (Ibidem, p. 17). No que tange aos silêncios, são "elementos que foram sistematicamente excluídos da narrativa com consequências ideológicas." (Ibidem, p. 18). Por fim, os potenciais são as "projeções sobre o que poderia ter acontecido além dos limites da narrativa." (Ibidem, p. 18).

\section{Literatura e Ensino por Tarefas: um plano de aula envolvendo ficções de fã}

Haja vista que a definição de Tarefa já foi apresentada, assim como os benefícios e as vantagens do uso da literatura no ambiente de ensino de uma segunda língua já foram discutidos, o que se propõe a seguir é a criação de uma aula que utilize o universo da escrita dos fãs para a elaboração de uma aula nos padrões do Ensino de Línguas por Tarefas.

\subsubsection{Objetivos}

O objetivo principal da tarefa a ser proposta é o de criar uma história alternativa ao enredo da obra Romeu e Julieta de William Shakespeare por meio de produção escrita pautada na observação e na análise de ficções de fã. Com relação aos objetivos subsidiários, eles envolvem o contato e a leitura com discussão e compartilhamento de opiniões referentes aos textos da manifestação literária dos fãs; o questionamento dos motivos pelos quais os fãs reescrevem histórias, e o fato de se despertar o interesse pelo envolvimento com a literatura.

\subsubsection{Material necessário}

O material utilizado para a realização da atividade serão duas ficções de fã, sendo uma delas o texto How Romeo and Juliet should have ended publicada no site fanfiction. net no dia 4 de janeiro de $2013^{18}$ e Romeo and Juliet: happily ever after ${ }^{19}$ com data de publicação no dia 5 de outubro de 2012.

18 Disponível em: https://www.fanfiction.net/s/9358676/1/How-Romeo-and-Juliet-should-haveended. Acesso em: 15 ago. 2018.

19 Disponível em: https://www.fanfiction.net/s/8612846/1/Romeo-and-Juliet-Happily-Ever-After. Acesso em: 15 ago. 2018. 


\subsubsection{Nível/tempo estimado}

Quanto ao nível, a atividade proposta neste artigo se mostra relevante aos níveis de proficiência B1 e B2, que são considerados os estágios de independência segundo o Quadro Europeu Comum de Referência. Destaca-se que esta atividade foi pensada em um cenário de sala de aula de aproximadamente 15 alunos. No que tange ao tempo estimado para a realização da tarefa, considera-se que 2 horas seja o tempo apropriado para a realização da atividade a ser proposta. Dessas 2 horas, 40 minutos serão destinados à Pré-Tarefa, 50 minutos à Tarefa e 30 minutos à Pós-Tarefa.

\subsection{As etapas da aula}

\subsubsection{A Pré-Tarefa}

A Pré-Tarefa, como aponta Ellis (2006), envolve o engajamento e a motivação para a realização da atividade em si. Assim, o que se propõe, inicialmente, é uma discussão acerca da obra Romeu e Julieta. O professor deve incentivar e ativar o conhecimento prévio dos alunos referente à obra shakespeariana com perguntas sobre o enredo da história. Pedir que o grupo resuma a história juntos é uma opção relevante, pois assim é garantido que todos relembrem a narração. Isso também favorece àqueles que, possivelmente, não estejam muito familiarizados com a obra em questão. Entretanto, é pertinente ressaltar que essa discussão inicial não deve ultrapassar o tempo de 10 minutos.

Feito isso, o professor conduz o questionamento e a discussão em torno do fim de Romeu e Julieta de modo a descobrir se os alunos concordam ou não com o fim da peça. Isso deve acontecer para que o docente possa pontuar que esse sentimento de descontentamento que muitas pessoas têm com relação a diferentes obras pode levar os fãs a reescrevê-las e as hospedarem em sites nos quais se veiculam tais produções livres. Assim, o professor apresenta, brevemente, a concepção de ficção de fã.

Ainda como parte da Pré-Tarefa, proporciona-se um texto de ficção de fã que exemplifique esse universo literário. Além disso, o contato com a escrita do fã é uma forma de prover um exemplo do que será esperado durante a tarefa. Isso se mostra relevante, pois Ellis (2006) considera que uma das opções para se estabelecer uma Pré-Tarefa decorre justamente da introdução de um modelo do que se espera ser produzido pelos alunos na Tarefa.

Para tanto, os alunos são divididos em dois grupos para que cada um leia uma ficção de fã. Terminada a leitura, cada grupo terá a oportunidade de discutir entre si o que foi lido. Eles podem opinar se preferem o final do fã ao original, ou se concordam ou não com o final alternativo. Essa discussão se mostra bastante tangível, uma vez que cada integrante do grupo faz uma leitura única, pois, como apresenta Dalvi (2012), a leitura 
deixa vir à tona quem somos. Por fim, os alunos são encorajados a resumir o que leram para o outro grupo. Assim todos têm acesso às duas produções de fãs levadas à aula. Uma breve discussão sobre qual das duas histórias alternativas à original thes pareceu mais interessante é outra forma de se buscar estabelecer não só comunicação, mas também apreciação literária.

\subsubsection{A Tarefa}

Concluída a leitura e discussão em torno das ficções de fã, propõe-se que seja feita uma discussão em grupos de 3 ou 4 alunos a respeito de como cada aluno acredita que a obra deveria terminar. Isso deverá ser feito para que eles criem o final alternativo para a obra Romeu e Julieta que julgarem mais adequado; lembrando que o leque de possibilidades dessa reescrita é consideravelmente amplo. Em seguida, cada um desses pequenos grupos redige sua própria ficção de fã. O professor deve ressaltar que só haverá uma história para cada grupo, portanto, todos devem participar ativamente tanto das discussões quanto da redação para que juntos cocriem uma ficção de fã.

Outro fator pertinente é o de que durante a realização da Tarefa, os alunos não podem ter acesso ao texto modelo que leram anteriormente. Isso se dá pelo fato de a atividade visar a criação de significado e não a manipulação da língua, além de promover o desenvolvimento da capacidade criativa da escrita decorrente da apreciação literária estabelecida na Pré-Tarefa.

\subsubsection{A Pós-Tarefa}

Na pós-tarefa, é dada aos grupos a oportunidade de compartilhar seus textos e ler o que o outro redigiu como proposta mais interessante para o fim da peça de Shakespeare. O intuito dessa leitura é a de que os alunos possam dar feedback ao que o outro grupo redigiu. No entanto, esses apontamentos devem ocorrer de modo a levar em consideração tanto a forma quanto o conteúdo em termos da mensagem, apontamento trazido por Ellis (2006) como maneira de se estabelecer a Pós-Tarefa.

Para que existam, portanto, esses feedbacks, os alunos devem ler o texto do outro grupo e fazer uma correção com foco na forma daquilo que fora escrito. Terminada a correção, os textos retornam aos devidos donos para que eles tenham acesso aos apontamentos feitos pelos integrantes do outro grupo.

Feito isso, é dada a oportunidade de que seja discutido, de forma aberta à classe, os pontos fortes e fracos que cada aluno identificou ao ler o texto do colega de sala. 0 intuito é que agora os envolvidos na atividade se posicionem como beta readers (que são os revisores das ficções de fã). Assim, o que deve ser instigado é o compartilhamento do que cada um achou criativo no texto do outro; explorando, portanto, aquilo que mais 
gostou ou aquilo que discordou e/ou mudaria no texto alheio. Acredita-se, assim, que apesar dessa discussão não evidenciar uma apreciação e/ou análise literária muito aprofundada, desperta certa criticidade e olhar mais atencioso ao enredo redigido pelo colega de sala, o que oferece mais uma chance de dividir opiniões e ideias diferentes em um uso autêntico da língua ao invés de repetição de estruturas gramaticais, por exemplo.

Em conclusão, o professor lança a oportunidade de os alunos avaliarem a atividade. Desse modo, levantam-se questões referentes à motivação dos alunos, no sentido de descobrir o quanto eles gostaram ou não de realizar a atividade. Esse é o momento para discutir quais os motivos que levam vários fãs a redigirem histórias tão diversas e variadas sobre universos dos quais gostam. Além disso, outra questão importante é a de o professor buscar saber dos alunos o que eles conseguiram perceber com relação ao processo de aprendizagem estabelecido na aula. Assim, o professor pode levantar questões relacionadas à habilidade de produção e compreensão oral trabalhadas especialmente nos momentos de discussão, e de compreensão e produção escrita desenvolvidas nos estágios de exposição e elaboração das ficções de fã.

Por fim, como forma de encerrar essa atividade e de aproximar ainda mais os alunos desse universo dos fãs, eles devem publicar o texto que redigiram durante a aula no site fanfiction.net. Uma sugestão é que isso seja feito como uma tarefa de casa. O professor pode instruí-los a ler e explorar mais ficções de fã durante a navegação no site para que os alunos compartilhem o que viram e leram no início da aula seguinte.

\section{Conclusão}

Com base na proposta de atividade pautada nos padrões do Ensino de Línguas por Tarefas apresentada previamente, nota-se a tangibilidade de se utilizar da literatura a fim de trazer contribuições relacionadas ao ensino de língua inglesa, especialmente no que diz respeito ao uso autêntico de língua.

Essa afirmação se justifica pelo fato de a atividade ter proporcionado, por meio da literatura das ficções de fã, a cocriação de significado e não a manipulação da língua tanto nos momentos de reflexão e discussão sobre a obra original, quanto no compartilhamento de ideias para que se redija um texto nos padrões de uma ficção de fã.

Além disso, outro fator que torna viável o apontamento da atividade trazida neste artigo ser condizente com os princípios do Ensino por Tarefas é o fato de a realização da Tarefa proporcionar um resultado, no caso, a elaboração de uma ficção de fãs pelos alunos. Ressalta-se ainda o fato de, além de a ficção de fã ter sido o resultado da Tarefa, ela foi o modelo oferecido na Pré-Tarefa que instigou a ideia de se fazer alterações na obra clássica e, portanto, chegar a esse resultado, que foi a ficção de fã. 
Outra observação pertinente se relaciona ao fato de esta atividade buscar espelhar uma prática que acontece no mundo real: a escrita. Obviamente que nem todos os alunos são de fato fãs da obra Romeu e Julieta. No entanto, ao simularem a posição de fã durante a aula, esses alunos assumem um papel que espelha o mundo real de um fã que escreveria uma história alternativa ao enredo original da literatura de Shakespeare. Assim, ao se colocar nessa posição, o aluno visa a alcançar um resultado a partir da sua produção escrita, que no caso se trata de uma ficção de fã publicada no universo on-line. Dessa forma, o direcionamento da atividade recai sobre o uso comunicativo e o resultado a ser alcançado em detrimento da manipulação da forma.

Por fim, observa-se que, por meio de um ensino inovador à tendência de se esquematizar e fragmentar o ensino de língua inglesa, como no caso do PPP, o Ensino de Línguas por Tarefas somado ao universo literário dos fãs possibilita o uso autêntico de língua ao invés de uma mera manipulação de conteúdos gramaticais.

\section{REFERÊNCIAS}

DALVI, M. A. Ensino de Literatura: algumas contribuições. In: PUZZO, M. B. et al (org.). Linguística Aplicada, Linguística e Literatura: intersecções profícuas. Campinas: Pontes Editores, 2012.

ELLIS, R. The Methodology of Task-Based Teaching. The Asian EFL Journal Quarterly, Road Town, v. 8, p. 19-45, set. 2006.

JENKINS, H. Lendo criticamente e lendo criativamente. Matrizes, São Paulo, n. 1, p. 11-24, 2012.

LLACH, P. A. Teaching language through literature: the waste land in the ESL classroom. La Rioja, n. 8, p. 7-17, 2007

NEVES, A. J. Cibercultura e Literatura Identidade e Autoria em Produções Culturais Parcipatórias e na Literatura de Fã (fanfiction). Jundiaí: Paco Editorial, 2014.

NUNAN, D. Task-based Language Teaching. New York: Cambridge University Press, 2004.

NUNAN, D. Task-based Language Teaching in the Asia Context: Defining 'Task'. The Asian EFL Journal Quarterly, Road Town, v. 8, p. 12-18, set. 2006.

PEACOCK, M. The effect of authentic materials on the motivation of EFL learners. ELT Journal, Oxford University Press, v. 51, n. 2, p. 144-156, 1997. 
PRABHU, N. S. Second Language Pedagogy. Oxford: Oxford University Press, 1987.

RICHARDS, J. C.; RODGERS, T. S. Task-Based Language Teaching. In: RICHARDS, J. C.; RODGERS, T. S. (org.). Approaches and Methods in Language Teaching. 2. ed. Cambridge: Cambridge University Press, 2001. p. 223-243.

SILVA, R. B. da. Using literary texts in the ESL classroom. R. Ci. Humanas, v. 1, n. 2, p. 171178, jul. 2001.

SKEHAN, P. Second language acquisition research and task-based instruction. In: WILLIS, D.; WILLIS, J. Challenge and Change in Language Teaching. Oxford, 1996.

WILLIS, J. A Framework for Task-Based Learning. Harlow: Longman, 1996. 